\title{
INVESTIGATING THE RELATIONSHIP BETWEEN METALINGUISTIC KNOWLEDGE AND L2 WRITING AMONG INTERMEDIATE-LEVEL ADULT TURKISH EFL LEARNERS
}

\author{
Fatma AYDIN \\ Anadolu University School of Foreign Languages, \\ Eskisehir, Turkey \\ f.aksoy@anadolu.edu.tr
}

Manuscript received 14 January 2019

Manuscript accepted 27 May 2019

https://doi.org/10.33736/ils.1246.2019

\begin{abstract}
The present study investigates the nature of metalinguistic knowledge among intermediate-level adult Turkish EFL learners, and the relationship between their metalinguistic knowledge and L2 writing in terms of complexity, accuracy and fluency. The participants of the present study are 78 intermediate-level adult Turkish EFL learners. The data collection instruments include Oxford Quick Placement Test (OQPT), Productive Metalinguistic Knowledge Test (PMKT), Receptive Metalinguistic Knowledge Test (RMKT) (adapted from Ellis, 2009) and opinion essays of a smaller group of the participants. The results revealed that intermediate-level adult Turkish EFL learners have moderate to high productive and metalinguistic knowledge. They are better at explaining why a L2 sentence is grammatically incorrect than referring to the exact grammar rule and using technical words for the grammatical features. The results also revealed that there is significant moderate correlation between metalinguistic knowledge and writing accuracy.
\end{abstract}

Keywords: Metalinguistic knowledge, L2 writing, complexity, accuracy, fluency

\section{Introduction}

On one hand, since the emergence of communicative approach to teaching and learning a second language (L2), communicative activities have come into prominence to enhance learners' fluency (Renou, 2001). Communicative language teaching, where the emphasis is on meaning as opposed to form or grammar, has

Investigating the Relationship between Metalinguistic Knowledge and L2 Writing among Intermediate-level Adult Turkish EFL Learners 
enabled language learners to use the modern foreign language but de-emphasised accuracy and metalanguage (Alderson \& Steel, 1994). Therefore, explicit L2 instruction has been glossed over (Gutierrez, 2013). In this sense, it is essential to consider the differences between learning one's mother tongue and learning a second language. For one, it is known that we learn our mother tongue without an awareness or knowledge about grammar (Renou, 2001). However, in learning a second language, linguistic accuracy is interrupted unless emphasis is placed on language form (Renou, 2001). Additionally, certain types of knowledge and skills in a second language may be difficult to obtain through untutored learning and thus require instruction (Gutierrez, 2013). Consequently, communicative language teaching has been criticised recently for neglecting attention to forms of language, and SLA research has begun to underscore the developmental value of "enhanced noticing" and "consciousness raising" in L2, paving the way for the language awareness movement to develop (Carter, 2003). Language awareness, also known as "knowledge about language", refers to "the consciousness of and sensitivity to the forms and functions of language" (Carter, 2003, p. 64).

On the other hand, language education in monolingual countries, such as Turkey, generally relies on formal teaching and learning of the target language, as these countries are acquisition-poor environments, in which foreign language learners cannot find many opportunities to hear and speak the foreign language (Yeşilyurt, 2005). In addition, learners' inabilities to be proficient listeners and speakers of the foreign language may be associated with this acquisition-poor environment. As a result, language awareness and explicit knowledge of language, and thus the metalinguistic knowledge about the foreign language being learned, emerges as particularly important.

Regarding the relationship between metalinguistic knowledge and foreign language proficiency, it is necessary to indicate that many researchers have stressed the importance of this issue even though some have not found clear evidence that metalinguistic knowledge contributes to the use of language in actual settings. Berry (2005), for example, points out that knowledge and use of metalanguage is likely to make the development of an L2 learner's metalinguistic awareness, which in turn is likely to foster second language development. Additionally, Zipke (2007) states that bilinguals' better ability to understand an unknown language compared to monolinguals may be attributed mostly to their greater metalinguistic awareness. Moreover, studies investigating learner strategies and good language learners reveal the benefits of metalinguistic skills such as treating language as a system and paying attention to form. Furthermore, some SLA researchers note usefulness of explicit L2 knowledge (Ellis, 1994; 2009). To exemplify, explicit L2 knowledge may make learners' establishment of links between form and meaning faster and thus facilitates L2 acquisition. It may also provide saliency for certain grammar features, which is likely to enable learners to notice them. In addition to this, explicit L2 knowledge may contribute to linguistic problem-solving where implicit knowledge is insufficient. It may help L2 learners to produce the target language consciously as well, which may turn into implicit learning through practice.

Although initial research in language awareness has shown findings on its behalf, some factors have been densely researched, such as "the role of 
metalanguage in learners' responses and whether metalinguistic knowledge can enhance or hinder language development" (Carter, 2003, p. 65). Of these limited number of studies, some found weak or no correlation between metalinguistic knowledge and L2 proficiency, while some others found positive correlations. The results are inconclusive and thus it is not clear how metalinguistic knowledge contributes to SLA. Therefore, further research is needed on the relationship between metalinguistic knowledge and $L 2$ proficiency in order to gain better insights into the role of metalinguistic knowledge in SLA development.

The purpose of this study is to find out the nature of metalinguistic knowledge that intermediate-level adult Turkish EFL learners have developed, and to examine the relationship between their metalinguistic knowledge and L2 production, operationalised in writing. In this study, L2 production has been chosen instead of overall L2 proficiency because it is assumed to represent learners' implicit knowledge of the foreign language, which is commonly referred to as procedural knowledge due to the processes engaged in the development and use of nondeclarative knowledge stores. In other words, the main concern of the present study is whether EFL learners are able to transfer their explicit knowledge (metalinguistic knowledge) to implicit knowledge or procedural knowledge (L2 production). L2 production is operationalised in writing (opinion essays) because it is believed to be easier to measure compared to oral production.

\section{Literature Review}

Considering that the main concern of the present study is whether EFL learners are able to transfer their explicit knowledge (metalinguistic knowledge) to implicit knowledge or procedural knowledge (L2 production), it is crucially important to clarify these terms first.

\section{Explicit and Implicit L2 Knowledge}

Prior to defining explicit and implicit knowledge, it is first necessary to make a distinction between explicit/implicit knowledge and explicit/implicit learning (Han \& Ellis, 1998). Schmidt (1994) states that explicit/implicit learning indicates the learning process, whereas explicit/implicit knowledge refers to what learners obtain at the end of the learning process, or the innate knowledge that is not learned at all (as cited in Han \& Ellis, 1998). When it comes to the difference between explicit and implicit L2 knowledge, the latter is simply "knowledge of language" (Han \& Ellis, 1998 , p. 5). Implicit L2 behaviour is evident in language behaviour and cannot be accessed independently of this behaviour (Bialystok, 1990). Mathews et al. (1989) maintain that implicit knowledge is memory-based rather than rule-based. Reber (1989), however, claims that implicit knowledge may be rule-based to some extent depending on Berko (1958), who reveals that child language learners are able to apply rules that they have internalised to new languages (as cited in Han \& Ellis, 1998).

Explicit knowledge, on the other hand, is simply "knowledge about the L2" (Han \& Ellis, 1998, p. 5). Han and Ellis (1998) break down explicit knowledge into Investigating the Relationship between Metalinguistic Knowledge and L2 writing among Intermediate-level adult Turkish EFL Learners 
analysed knowledge and metalanguage. Analysed knowledge is the knowledge about the L2 items and structures of which learners are not fully conscious, whereas metalanguage is the language used to describe or analyse the language of which learners are fully conscious. VanPatten and Benati (2010) state that declarative knowledge is sometimes used as a synonym for explicit knowledge. Declarative knowledge is defined as some kind of conscious awareness of the rules and the skill of verbalising what is known.

The two factors that distinguish implicit L2 knowledge from explicit L2 knowledge are accessibility and awareness (Han \& Ellis, 198). Implicit knowledge is easily accessed in tasks that require fluent language performance, is unanalysed and thus held without awareness. Explicit knowledge, however, is not easily accessed without controlled effort and thus is employed in tasks requiring careful planning and monitoring. In addition to this, explicit knowledge is analysed and model-based and consequently held consciously. Furthermore, explicit knowledge may involve metalingual knowledge, which is addressed below along with its counterpart, metalinguistic knowledge.

\section{Metalingual and Metalinguistic Knowledge}

The term "metalingual" is used as the adjective of "metalanguage" although there is controversy over the uses of the two terms. Prior to dealing with this controversy, it is first necessary to define the term "metalanguage". Having been the property of linguistics, philosophy, logic and semantics for long, the term "metalanguage" is currently found increasingly in the applied linguistics literature (Berry, 2005). It is used with reference to such issues as the language use of language teachers, language of pedagogic grammars and the relationship between language awareness and language learners' proficiency. Berry (2005) stated that metalanguage is a language that is used to talk about, discuss, describe or make statements about a language. It may be used to talk about another language as well. In addition to these definitions, Webster's Encyclopedic Unabridged Dictionary of the English Language (1996), a non-specialist source, describes metalanguage as "any language or symbolic system used to discuss, describe or analyse another language or symbolic system" (as cited in Berry, 2005, p. 5)

In this respect, "metalingual" is the knowledge or awareness of "metalanguage" (Berry, 2005; Ellis, 1994). Additionally, Dakowska (1993) and Ellis (1994) use the term "metalingual" for the knowledge and awareness of language, too. Berry (2005), however, uses the term "metalinguistic" for the knowledge and awareness of language. Gutierrez (2012) makes a distinction between metalinguistic knowledge and metalingual knowledge noting that metalinguistic knowledge is the explicit knowledge of the language. In this sense, metalinguistic knowledge and explicit knowledge are used interchangeably (Gutierrez, 2012). Gutierrez (2012) further states that metalinguistic knowledge is measured through identification of speech parts, identification and correction of errors and verbalisation of rules. Metalingual knowledge, on the other hand, is the knowledge of metalinguistic terminology or the knowledge of metalanguage. Considering this, metalingual

Investigating the Relationship between Metalinguistic Knowledge and L2 writing among Intermediate-level adult Turkish EFL Learners 
knowledge can be measured checking whether learners use metalanguage to identify and correct errors.

Roehr (2007) points out "that metalinguistic knowledge has been operationalized as learners' ability to correct, describe and explain L2 errors" ( $p$. 172). Metalinguistic awareness, on the other hand, is the conscious knowledge of the formal aspects of the language, specifically grammar (Renou, 2001). Some SLA researchers claim that metalinguistic awareness sheds light on the developing L2 competence (Arthur, 1980; Gass, 1994; Masny, 1991, as cited in Renou, 2001). Considering that metalinguistic awareness is often measured using grammaticality judgment tests and error correction and justification tasks, Kellerman (1986) and Sharwood Smith's (1988) claim that learners' ability to judge whether a sentence is grammatically correct or not shows their competence also supports the role of metalinguistic awareness in L2 competence (as cited in Renou, 2001). Moreover, Germain and Seguin (1995) maintain that metalinguistic awareness, operationalised as knowledge about grammar, is essential for a number of reasons. First of all, knowledge about grammar is important because L2 learners are required to sit for a variety of language exams that are based on explicit knowledge such as placement tests and proficiency exams. Second, metalinguistic awareness helps L2 learners better understand input. Third, knowledge about language enhances L2 learners' motivation and reduces stress in learning a L2. Furthermore, Andrews (2005) signifies that metalinguistic awareness, which is the awareness of the language itself, its structures and functions, enables the speakers of a language to think about and use that language consciously. Similarly, Kuile and Weldhuis (2010) state that metalinguistic awareness is likely to provide learners of a $L 2$ with the ability to discuss different ways of using that language. Lack of metalinguistic awareness, on the other hand, may result in difficulty in comprehending the structure of a language (Swain \& Lapkin, 1995).

\section{The Relationship between Metalinguistic Knowledge and L2 Proficiency}

Research on the relationship between metalinguistic knowledge/awareness and $L 2$ proficiency dates back to Steel and Alderson (1994), in which a battery of tests of metalinguistic knowledge, language aptitude, grammatical accuracy in French and French linguistic proficiency were constructed and the relations amongst these measures were explored. In this study, moderate correlations were found between metalinguistic knowledge and French grammatical accuracy, and metalinguistic knowledge and language aptitude. However, proficiency in French reading did not correlate with either aptitude or metalinguistic knowledge but was correlated with French grammatical accuracy only moderately. These preliminary findings indicate that metalinguistic knowledge makes almost no contribution to L2 proficiency. Subsequently, Alderson, Clapham, and Steel (1997) administered the battery to firstyear students of French in six more British universities this time. As a result, the relationship metalinguistic knowledge and language proficiency was reported to be weak. They note that there is no evidence to support the belief that students with the highest metalinguistic knowledge will perform better at French or develop their French at a high rate than others.

Investigating the Relationship between Metalinguistic Knowledge and L2 writing among Intermediate-level adult Turkish EFL Learners 
On the other hand, there have been some other studies that found a significant relationship between metalinguistic knowledge and L2 proficiency. Renou (2000), for instance, found that the participants who had been exposed to grammar approach were better at correcting grammar rules and providing the rule in a judgment test created to assess metalinguistic awareness. Additionally, a significant correlation was found between the judgment test and a proficiency test, which indicates that metalinguistic awareness may have a role in L2 proficiency. Renou (2001) revised her study and found a moderate significant correlation between both oral and written versions of the judgment test and French proficiency for the entire sample. However, the correlation was non-significant for the participants who had been exposed to communicative approach, whereas it remained significant and even increased in the case of the participants who had been exposed to grammar approach. In other words, increases in metalinguistic awareness are associated with increases in proficiency once learners have been exposed to explicit grammar instruction; however, indicating that metalinguistic awareness may be only one of the factors influencing L2 development along with many others. In a different L2 environment, Elder and Manwaring (2004) also investigated the role of metalinguistic knowledge in learning a foreign language among Chinese second language learners. Results revealed that $\mathrm{L} 2$ metalinguistic knowledge is low among Chinese second language learners. However, surprisingly, the participants who had studied L2 for a shorter term performed better in grammatical knowledge. With regard to the relationship between metalinguistic knowledge and L2 performance, the relationship was stronger for the late-starters than the participants who had studied L2 for a longer time, indicating that late-starters are more reliant on grammatical knowledge for L2 success. In another L2 context, Roehr (2007) carried out an investigation to find out the relationship between L2 proficiency and L2 metalinguistic knowledge among advanced university-level English learners of German. The secondary aim of the current study is to investigate the relationship between the ability to correct, describe and explain L2 errors and language-analytic ability, which refers to the ability to identify the grammatical role of parts of speech in $L 2$ sentences. Consequently, a strong positive correlation was found between $L 2$ proficiency and metalinguistic knowledge. Another important finding of the current study is that the ability to correct, describe and explain L2 errors and the ability to identify the grammatical of parts of speech in L2 sentences may be the components of the same complex construct: metalinguistic awareness. Alipour (2014), investigated the issue among university-level Iranian EFL learners. As a result of a bivariate regression analysis, a moderate significant relationship was found between metalinguistic knowledge and L2 proficiency (operationalised as grammar knowledge assessed by a cloze test) among Iranian EFL learners. Tokunaga (2014), reported that the participants (low-intermediate level Japanese university students) had difficulty identifying basic parts of speech and parts of sentences, which suggests that many of them lack the metalinguistic knowledge. In addition to this, significant correlations were found between the participants' proficiency test scores and metalinguistic knowledge, with the strongest correlation being between reading scores and metalinguistic knowledge. Similarly, Wistner (2014) investigated metalinguistic knowledge, language learning aptitude, and L2 procedural knowledge

Investigating the Relationship between Metalinguistic Knowledge and L2 writing among Intermediate-level adult Turkish EFL Learners 
among Japanese learners of English using the Rasch model and structural equation modelling. He found that metalinguistic knowledge and language learning aptitude are two distinct factors, and metalinguistic knowledge statistically predicted L2 procedural knowledge (writing) in terms of complexity, accuracy, and fluency, whereas language learning aptitude was not a statistically significant predictor of those variables.

More recently, Gutierrez (2016) examined the two components of explicit knowledge, namely, analysed knowledge and knowledge of metalanguage, and their relationship to different skills and aspects of L2 proficiency. The findings revealed that the analysed knowledge is significantly correlated with more components of L2 proficiency than knowledge of metalanguage. It is reported that these results point to a larger role of analysed knowledge in L2 proficiency than of knowledge of metalanguage. In another recent study, Aydın (2018) found that intermediate-level adult Turkish EFL learners studying at a large-scale Turkish university had L2 metalinguistic knowledge. In addition, a correlation analysis and a series of bivariate and multiple regression analyses revealed that L2 metalinguistic knowledge significantly contributes to L 2 writing achievement explaining $19.9 \%$ of the variance in participants' writing exam scores.

In sum, a review of the studies investigating the relationship between metalinguistic knowledge/awareness and L2 proficiency reveals that there is controversy over this research area. However, a good number of research studies underscore the importance of metalinguistic knowledge in L2 development especially in the case of $L 2$ learners who have been exposed to explicit grammar instruction. Still, related research is limited, and varies especially in terms of L1-L2 combinations. Therefore, further research is required to gain better insights into this controversial issue, which is likely to contribute to L2 development.

\section{Methodology}

This quantitative study has two phases. The first phase investigates the nature of metalinguistic knowledge that intermediate-level adult Turkish EFL learners have developed, whereas the second phase explores the relationship between L2 metalinguistic knowledge and writing complexity, accuracy and fluency.

\section{Participants}

Convenience sampling was employed and 78 Turkish EFL students from five intact classes, who were studying at a state university in Turkey, participated in the present study. The participants were between 18 and 22 years old. They were all monolinguals with their native language being Turkish, and no participant included in the current study had an extended stay in an English-speaking country. They had been learning English for almost ten years and reported having been exposed to mostly explicit grammar instruction throughout those years. It is worth noting that the participants seldom have contact with native speakers in authentic listening and speaking situations.

Investigating the Relationship between Metalinguistic Knowledge and L2 writing among Intermediate-level adult Turkish EFL Learners 


\section{Instruments}

Three instruments were employed for the purposes of the present study. The first instrument is Oxford Quick Placement Test (OQPT), which gives information about students' language ability in relation to the Common European Framework of Reference for Languages (CEFR), and thus is widely used in research (Wang \& Treffers-Daller, 2017). The OQPT is appropriate for the purposes of the present study because it consists of question types that the participants are familiar with and provides item variety. It measures L2 learners' English vocabulary knowledge such as word meanings, collocations, synonyms and antonyms, and phrases, and grammar knowledge such as tense, passive voice and counterfactual knowledge. The maximum score students can obtain is 60 . The time allocated for the OQPT is $30-45$ minutes.

Second, the researcher developed a Metalinguistic Knowledge Test (MKT), measuring the explicit knowledge of the participants about their foreign language. The MKT consists of two sub-tests, namely, Productive Metalinguistic Knowledge Test (PMKT) and Receptive Metalinguistic Knowledge Test (RMKT). The PMKT (adapted from Ellis, 2009) consists of 17 English sentences that are grammatically incorrect. The participants were asked to a) underline the incorrect part of the sentence, b) correct the sentence, and c) explain why it is incorrect referring to the grammar rules. The grammatical structures included in the PMKT are verb complements, regular past tense, yes/no questions, modal verbs, indefinite article, possessive 's, plural $-s$, third person $-s$, comparatives and superlatives, adverb placement, since/for, relative clauses, unreal conditionals, question tags, ergative verbs, embedded questions and questions without auxiliaries. These structures (except the questions without auxiliaries) were chosen based on the Marsden study, which was built on the Han and Ellis (1998), and aimed to develop a battery of tests that would provide relatively separate measures of implicit and explicit knowledge. It is worth noting that the participants are assumed to know all of these 17 structures because all of these structures are included in the grammatical content of the participants' current textbook or in that of the lower levels.

The PMKT was scored in terms of rule explanation, on a 4-point Likert scale $(0,1,2,3)$, and technical language use, on a 3-point Likert scale $(0,1,2)$. Rule explanation refers to the participants' ability to recognise the incorrect part and correct it explaining the grammar rule. Technical language use, on the other hand, refers to the participants' knowledge of metalanguage and the other technical terms that can be used to explain the grammar rules. Table 1 shows the scoring procedures. Therefore, the scores that could be obtained from each question in the PMKT range between 0 and 5, making the maximum score 85 (17x5). It is also worth mentioning that the technical words that the participants were expected to use in their rule explanation were listed for each question, and this was used as a rubric in scoring technical language use. One third of the PMKT papers $(\mathrm{N}=26)$ were graded by two raters (a co-rater along with the researcher) who negotiated on the discrepancies and tried to completely agree on each question for each participant. The co-rater was an experienced English instructor, who had been working at the same institution for 12 years and worked in testing unit for a long time. The

Investigating the Relationship between Metalinguistic Knowledge and L2 writing among Intermediate-level adult Turkish EFL Learners 
researcher rated the rest of the papers on her own but negotiated with the co-rater when problems arose.

Table 1

Scoring Procedures for the PMKT

\begin{tabular}{lll}
\hline Rule Explanation & Technical Language Use \\
\hline $\mathbf{0}$ & $\begin{array}{l}\text { The grammatical error is underlined } \\
\text { only. }\end{array}$ & No technical terms \\
$\mathbf{1}$ & $\begin{array}{l}\text { The grammatical error is underlined and } \\
\text { the correct sentence is written. }\end{array}$ & $\begin{array}{l}\text { There is only } 1 \text { technical term in the } \\
\text { rule explanation. }\end{array}$ \\
$\mathbf{2}$ Either the correction or the rule & $\begin{array}{l}\text { There are two and more technical } \\
\text { explanation is partial. }\end{array}$ \\
$\mathbf{3} \begin{array}{l}\text { Both the correction and the rule } \\
\text { explanation are complete. }\end{array}$ & -
\end{tabular}

The RMKT consists of a 231-word reading text (adapted from http://www.esl-lounge.com/student/reading-intermediate.php) and a list of 25 grammatical features. The participants were asked to find one example of each grammatical feature from the reading text. The participants were also asked to write the line of the example they found because there was more than one example for some of the grammatical features. The grammatical structures covered in the RMKT were the same with the ones in the PMKT. Concerning the scoring of the RMKT, the correct examples received 1 point, while the incorrect ones received 0 , making the maximum score 25.

For reliability and validity concerns, expert opinion was gathered for the PMKT and the RMKT. The experts were five experienced English instructors and one English Language Teaching (ELT) professor. Additionally, the two tests were piloted with a group of $17 \mathrm{EFL}$ learners at the same institution, who were sharing similar features with the actual participants of the present study. The reliability of the PMKT and RMKT was $\alpha=.87$ and $\alpha=.90$, respectively. In addition, a significantly positive strong relationship was found between the PMKT and the RMKT, $r=.848, p<0.01$.

The reading text in the RMKT had already been simplified to ensure that the participants would comprehend it easily; however, the participants in the pilot study were asked several comprehension questions to check its comprehensibility, and no problems were encountered. As a result of the pilot study, some minor changes (lexical and grammatical alterations) were made in the PMKT as well, and instructions were prepared for the participants.

The PMKT and the RMKT were both untimed tests, which means that test takers could answer the questions at their own pace. A practice item was provided for each test in the beginning.

Third, 38 of the participants were asked to write opinion essays (second phase of the study). The topic was as: “People don't need to learn a foreign language because computers can translate all languages. Do you agree or disagree with this statement? Use specific reasons and examples to support your answer." It was a timed in-class writing task. The participants had to complete the task in one class hour (40 minutes). The essays were first graded using a holistic rubric (poor,

Investigating the Relationship between Metalinguistic Knowledge and L2 writing among Intermediate-level adult Turkish EFL Learners 
inadequate, adequate, good, and very good). Then they were graded on the Profile of Larsen-Freeman (2006). Larsen-Freeman (2006) conducted an in-depth analysis on English language learners' performance. Through her study, Larsen-Freeman (2006) introduced a profile, which utilised T-units in assessing both oral and written language productions in terms of complexity, accuracy, and fluency. Larsen-Freeman (2006) defined writing complexity, accuracy, and fluency as follows:

1) Complexity: The total number of clauses divided by the total number of Tunits.

2) Accuracy: The proportion of error-free T-units to total T-units (in terms of lexical, morphological, and syntactic errors).

3) Fluency: The average number of words per T-unit.

According to Housen and Kuiken (2009), "CAF (Complexity-AccuracyFluency) have been used both as performance descriptors for the oral and written assessment of language learners as well as indicators of learners' proficiency underlying their performance; they have also been used for measuring progress in language learning" (p. 461).

The T-units, on the other hand, were determined based on the T-unit Guideline developed by Polio (1997). "A T-unit is defined an independent clause and all its dependent clauses" (Polio, 1997, p. 138). T-units are usually utilised to analyse written and spoken discourse because research has revealed that T-units are strongly correlated to language proficiency (Ellis \& Barkhuizen, 2005; WolfeQuintero, Inagaki, \& Kim, 1998).

All of the essays were rated by the researcher and the same co-rater who also rated the PMKT. The raters used the "Guidelines for T-units, Clauses, Word Counts and Errors" by Polio (1997) in rating the essays. The raters negotiated and tried to reach a complete agreement on each essay.

\section{Data Collection Procedures}

The data collection took three weeks. In the first week, the OQPT was administered. In the second week, the PMKT and the RMKT were administered. The PMKT was administered before the RMKT because the grammatical features in the RMKT would have affected how the participants explained the grammatical rule for the incorrect parts of the sentences if they had been administered the RMKT before the PMKT. Finally, in the third week, the participants wrote the opinion essays.

\section{Results}

\section{What is the Nature of Metalinguistic Knowledge that Intermediate-level Adult Turkish EFL Learners have Developed?}

To begin with, the participants' scores from the OQPT, PMKT (rule explanation and use of technical words) and RMKT were computed, and the descriptive statistics were calculated (See Table 2).

Investigating the Relationship between Metalinguistic Knowledge and L2 writing among Intermediate-level adult Turkish EFL Learners 
Table 2

Descriptive statistics: OQPT, PMKT and RMKT

\begin{tabular}{lccccc}
\hline & Full Score & Minimum & Maximum & Mean & SD \\
\hline OQPT & 60 & 21 & 54 & 30.97 & 6.18 \\
PMKT & 85 & 15 & 70 & 40.64 & 14.28 \\
RMKT & 25 & 1 & 23 & 12.45 & 5.73 \\
Rule Explanation & 51 & 4 & 44 & 27.49 & 9.12 \\
Use of Technical Words & 34 & 0 & 26 & 13.15 & 5.93 \\
\hline
\end{tabular}

Once the descriptive statistics were calculated, tests of normality were carried out for the OQPT, PMKT and RMKT, and the extreme values were found. According to Tabachnick and Fidell (2012), the Skewness Kurtosis values must be between -1.5 and +1.5 for a test to be considered to have normal distribution so that parametric tests can be conducted. The tests of normality revealed that the PMKT and RMKT showed normal distribution, while the OQPT did not.

For the OQPT, it is clear that the participants' language abilities differed although all of them had been placed at the same proficiency level (Intermediate). Ten of the participants were at pre-intermediate level; 54 participants were at intermediate level; 13 participants were at upper-intermediate level, and one participant was at advanced level according to their scores from the OQPT. It is possible that the participants had made varying levels of progress in terms of their language abilities since the beginning of the term (for six to seven weeks).

As to the PMKT and RMKT, when we look into the quartiles and the interquartile ranges, as shown in Table 3, 21 participants who obtained 29 and less from the PMKT are low achievers, and they make up 27 percent of the whole sample. Thirty-eight participants (or 49 percent of sample) obtained between 30 and 52 from the PMKT are moderate achievers. Nineteen participants (or 24 percent) obtained 53 and more from the PMKT are high achievers. When it came to the RMKT, 19 participants (or 24 percent) obtained seven and less are low achievers. Thirty-eight participants (or 49 percent) got between 8 and 16 from the RMKT were moderate achievers. Twenty-one participants (or 27 percent) scored 17 and more from the RMKT were high achievers.

Table 3

Quartiles and the interquartile range: PMKT and RMKT

\begin{tabular}{cccccccccc}
\hline & Q1 & N & P & Q2 & N & P & Q3 & N & P \\
\hline PMKT & $29-$ & 21 & $27 \%$ & $30-$ & 38 & $49 \%$ & $53+$ & 19 & $24 \%$ \\
& & & & 52 & & & & & \\
RMKT & $7-$ & 19 & $24 \%$ & $8-16$ & 38 & $49 \%$ & $17+$ & 21 & $27 \%$ \\
\hline
\end{tabular}

Second, in order to find out if the participants' productive and receptive metalinguistic knowledge significantly differed from each other, their scores from the PMKT and RMKT were first converted to 100 to equalise them. Then a paired samples t-test was carried out. The results revealed that although the participants performed slightly better in the PMKT $(M=47.82, S D=16.74)$ than in the RMKT 
$(M=49.79, S D=22.92)$, this difference was not statistically significant, $t(77)=-1.025$, $p=.308$.

Third, a correlation analysis was carried out in order to see the relationships among the participants' language ability and productive and receptive metalinguistic knowledge (See Table 4). A significant weak correlation was found between OQPT and PMKT, $r=.248, p<0.05$. This finding suggests that as EFL learners' language ability increases, their productive metalinguistic knowledge may increase as well. In addition, a significant high-to-moderate correlation was found between PMKT and RMKT, $r=.672, p<0.01$. This finding indicates that EFL learners' productive metalinguistic knowledge and receptive metalinguistic knowledge go hand in hand.

Table 4

Correlation analysis: OQPT, PMKT and RMKT

\begin{tabular}{llll}
\hline & OQPT & PMKT & RMKT \\
\hline OQPT & 1 & $.248^{*}$ & .107 \\
PMKT & & 1 & $.672^{* *}$ \\
RMKT & & 1 \\
\hline${ }^{*}$ Correlation is significant at the 0.05 level (2-tailed). \\
$* *$ Correlation is significant at the 0.01 level (2-tailed).
\end{tabular}

The two types of scores that the participants obtained from the PMKT, namely, Rule Explanation and Use of Technical Words, were also compared. First, they were converted to 100 as the scoring procedures varied (See Table 1). Then a paired samples $t$-test was run. Results revealed a statistically significant difference between the participants' scores from the PMKT in terms of rule explanation $(M=53.90, S D=17.88)$ and use of technical words $(M=38.69, S D=17.45), t(77)=22.10$, $p<.001$. This finding indicates that the participants performed significantly better in the rule explanation than in the use of technical words. In other words, the participants were able to explain why a $\mathrm{L} 2$ sentence is grammatically incorrect without much use of metalanguage.

What is the Relationship between L2 Metalinguistic Knowledge and Writing Complexity, Accuracy and Fluency?

As stated above, $38 \mathrm{EFL}$ learners participated in the second part of the present study and they were asked to write opinion essays. Of these 38 participants, those who were either below or above intermediate level according to their scores from the OQPT, were excluded from the final data set. Therefore, the sample size shrank to 27 for the second part of the present study.

In order to find out the CAF measures (complexity, accuracy and fluency), the total number of T-units, error-free T-units, clauses and words were calculated for each of the 27 essays. To find out complexity, the total number of clauses was divided by the total number of T-units. For accuracy, the total number of error-free T-units was divided by the total number of T-units. As to the fluency, lastly, the total number of words was divided by the total number of T-units. Thus, each participant

Investigating the Relationship between Metalinguistic Knowledge and L2 writing among Intermediate-level adult Turkish EFL Learners 
had a complexity, an accuracy and a fluency score. These scores were computed and the descriptive statistics were calculated (See Table 5).

Table 5

Descriptive statistics: CAF measures

\begin{tabular}{lcccc}
\hline & Minimum & Maximum & Mean & SD \\
\hline Complexity & 1.14 & 2.69 & 1.54 & .27 \\
Accuracy & .18 & .88 & .54 & .17 \\
Fluency & 8.25 & 20.15 & 12.07 & 2.32 \\
\hline
\end{tabular}

After that, for the purpose of standardisation, these scores were converted into z-scores, which is a standard score used to measure how many standard deviations below or above the mean a raw score is, and then into t-scores $(50+10 z)$. A correlation analysis revealed that there were negative but non-significant correlations between complexity and accuracy, and accuracy and fluency (See Table $6)$. The correlation analysis also revealed a high positive significant correlation between complexity and fluency, $r=.788, p<0.01$, which indicates that the more complex an EFL learner's writing is, the more fluent it is.

Table 6

Correlation analysis: CAF measures

\begin{tabular}{|c|c|c|c|}
\hline & Complexity & Accuracy & Fluency \\
\hline Complexity & 1 & -.223 & $.788^{* *}$ \\
\hline Accuracy & & 1 & -.312 \\
\hline Fluency & & & 1 \\
\hline
\end{tabular}

This standardisation also enabled us to compare the participant's scores from these three separate measures. Three sets of paired samples t-tests displayed that although the participants' essays were slightly more complex than being accurate and fluent, there were no statistically significant differences across their scores from the complexity $(M=50.04, S D=10.53)$, accuracy $(M=48.89, S D=9.74)$ and fluency ( $M=48.89, S D=10.40$ ) measures.

To find out the relationship between $L 2$ metalinguistic knowledge and writing complexity, accuracy and fluency, another correlation analysis was conducted with the variables being PMKT, RMKT and the CAF measures. As Table 7 displays, PMKT does not correlate with any of the CAF measures significantly, indicating that there is not a significant relationship between productive metalinguistic knowledge and complexity, accuracy and fluency of writing among intermediate level adult Turkish EFL learners. However, there is a significant moderate correlation between RMKT and accuracy of writing, $r=.405, p<0.05$. This finding suggests that as receptive metalinguistic knowledge increases, so does accuracy of writing among intermediate level adult Turkish EFL learners.

Investigating the Relationship between Metalinguistic Knowledge and L2 writing among Intermediate-level adult Turkish EFL Learners 
Table 7

The relationship between 12 metalinguistic knowledge and writing complexity, accuracy and fluency

\begin{tabular}{llllll}
\hline & PMKT & RMKT & Complexity & Accuracy & Fluency \\
\hline PMKT & 1 & $.706^{* *}$ & -.107 & .283 & -.265 \\
RMKT & & 1 & -.186 & $.405^{*}$ & -.042 \\
\hline
\end{tabular}

* Correlation is significant at the 0.05 level (2-tailed).

** Correlation is significant at the 0.01 level (2-tailed).

\section{Discussion}

The present study was conducted to find out the nature of metalinguistic knowledge among intermediate-level adult Turkish EFL learners, and the relationship between this knowledge and the complexity, accuracy and fluency of their writing. Writing was specifically chosen because it is the embodiment of $L 2$ production, and is easier to measure objectively compared to speaking. The present study revealed that the participants differed in their general language ability although they had all been placed at intermediate level at their school. In interpreting this preliminary finding, it should be considered that the placement test used as a data collection instrument in the present study (OQPT) was administered to the participants almost two months after the term began. In other words, they had been studying at intermediate level for almost two months when the present study was being conducted. In this sense, it is likely that the participants made varying levels of progress in terms of their overall language ability. Some seem to have kept up with the learning objectives and the requirements of the proficiency level that their school placed them, while some others have made far more progress, and still some others seem to have deteriorated with regard to their general L2 ability.

The findings also suggest that despite the variation in the participants' general language ability, they seem to be similar to each other in terms of their metalinguistic knowledge. The statistical analyses signal that the participants of the present study are high to moderate achievers of metalinguistic knowledge. In addition, their productive metalinguistic knowledge and receptive metalinguistic knowledge are quite similar to each other. These findings indicate that intermediatelevel adult Turkish EFL learners are able to notice the grammatical inaccuracy in a L2 sentence, correct it and explain why it is incorrect referring to the grammar rules, and they can also recognise metalinguistic terms and show examples for them in a text. Furthermore, their productive metalinguistic knowledge and receptive metalinguistic knowledge are strongly related to each other. Apparently, these two different knowledge types feed each other in this case. Therefore, it can be maintained that the more chances are provided for EFL learners to produce metalinguistic explanations in a foreign language, the more likely they are to recognise the metalinguistic structure of that language. Similarly, the more awareness is raised for learners of the metalinguistic structure of a foreign language, the better they are likely to become at producing metalinguistic explanations in that foreign language. However, although the participants did not differ in their performance in the PMKT and RMKT, they performed significantly better in the rule 
explanation than in the use of technical words in the PMKT. This finding indicates that although the participants were able to recognise the linguistic terms in the RMKT as well as they were able to correct a grammatically inaccurate $L 2$ sentence along with explaining why it was incorrect, their performance with regard to using linguistic terms in their explanations was not good enough. In other words, the findings of the present study indicate that intermediate-level adult Turkish EFL learners can recognise examples of metalanguage in a text; however, they cannot produce them on their own. Additionally, findings of the present study point out a significant correlation between general L2 ability and productive metalinguistic knowledge. This means that as the productive metalinguistic knowledge increases, so does the general L2 ability, or vice versa. In this sense, it is possible for productive metalinguistic knowledge to have a positive effect on general language ability. In this sense, the present study appears to be in line with Renou, (2000; 2001), Elder and Manwaring, (2004), Alipour, (2014) and Tokunaga, (2014), who have found a significant relationship between metalinguistic knowledge and L2 proficiency. However, as far as the Turkish context is concerned, the findings of the present study do not corroborate Yeşilyurt (2005), who did not find any significant evidence for the role of metalinguistic knowledge in foreign language proficiency. This difference may be because in Yeşilyurt (2005) foreign language proficiency was measured using multiple-choice tests for reading, listening and language structure, and the participants were asked to write a paragraph (100-150 words) for the writing test. This means that the participants produced very little; therefore, it does not seem much possible for this study to find out the role of metalinguistic knowledge in the actual use and production of language.

For the second part of the study, a smaller group of participants wrote opinion essays. Of them those whose OQPT scores did not fall in the intermediaterange were excluded from the present study in order to reach at more reliable and robust findings. It was found that the participants were similar to each other in terms of the complexity, accuracy and fluency of their writing. As to the interrelationships among these three different measures, the findings need to be interpreted cautiously, as the sample size is not large enough. The findings indicate that writing accuracy negatively correlates to complexity and fluency, which is necessary to emphasize although it is statistically non-significant probably because of the small sample size. This finding suggests that as the complexity, namely the proportion of clauses to T-units, and fluency, namely the number of words per Tunits, increase, intermediate adult Turkish EFL learners participating in this study are likely to make more grammatical mistakes. It is possible that EFL learners may have not been able to fully internalize the grammar rules they have been taught. It is also possible that they may be much more successful in a multiple-choice grammar test than they are in writing where they are supposed to transform declarative knowledge into procedural knowledge, or where they need to make use of metalinguistic knowledge rather than linguistic knowledge. On the other hand, complexity and fluency are significantly strongly correlated. This finding is expected because of the way complexity and fluency have been defined in this study. In other words, because complexity and fluency are concerned with the proportion of clauses 
to the total number of T-units and words to the total number of T-units respectively, it is not surprising that they have direct relationship to a great extent.

As to the relationship between metalinguistic knowledge and complexity, accuracy and fluency of writing among intermediate-level adult Turkish EFL learners, the only significant correlation is between receptive metalinguistic knowledge and writing accuracy. This finding indicates that as the receptive metalinguistic knowledge increases among intermediate level adult Turkish EFL learners, their writing accuracy increases as well. It seems that productive metalinguistic knowledge also has a positive relationship with writing accuracy although it is statistically non-significant. These findings along with the significant correlation between productive metalinguistic knowledge and writing accuracy suggest that overall metalinguistic knowledge seems to be related to writing accuracy. These findings may also suggest that metalinguistic knowledge is likely to have a positive effect on writing accuracy. However, the small sample size recruited for the second part of the present study prevents us from reaching at more reliable and generalisable findings.

Regarding the relationship between metalinguistic knowledge and L2 writing, the findings of the present study are congruent with those of Wistner (2014) to some extent. Wistner (2014) found that metalinguistic knowledge statistically predicted L2 writing in terms of complexity, accuracy, and fluency, whereas the present study found a significant correlation between metalinguistic knowledge and writing accuracy only. The differences between the two studies may be attributed to the CAF measures, the sample size and the statistical procedures employed. First of all, in the present study, each of CAF measures refers to one single thing. Complexity refers to the proportion of clauses to T-units; accuracy refers to the proportion of error-free T-units to the total number of T-units, and fluency refers to the proportion of words to the T-units. In Wistner (2014), however, complexity refers to word per T-unit, words per dependent clauses, clauses per T-unit and dependent clauses per clause; fluency refers to number of T-units and clauses and word per Tunits; accuracy refers to words per error-free T-units, error-free T-units per T-units and error-free clauses per clause. Apparently, they are more complex and thoroughly defined, and thus may have measured what they were supposed to measure better. In other words, the CAF measures in Wistner (2014) appear to be more valid. Second, the sample size in Wistner (2014) is large, which made it possible to reach at more reliable and generalizable findings. Lastly, the larger sample size and the strong correlations between the dependent and independent variables also made it possible to carry out advanced statistical procedures such as Rash analysis and SEM, which revealed more robust and conclusive results.

\section{Pedagogical Implications}

The findings of the current study can contribute to the importance of metalinguistic knowledge in second language acquisition among adult EFL learners, which has been regaining attention recently after having been overshadowed by communicative language teaching for a long time. Metalinguistic knowledge is likely to enable teachers and learners to explain, clarify, practice, use and reflect on the use of the target language, which will improve their understanding of linguistic constructs.

Investigating the Relationship between Metalinguistic Knowledge and L2 writing among Intermediate-level adult Turkish EFL Learners 
Considering that metalinguistic knowledge benefits language learning, teachers may help learners to connect their metalinguistic knowledge to language production in the forms of production exercises and writing tasks so that they can learn target grammar structures more easily and reinforce what they have already learned. Teachers can show learners how the written language may be a good source of information about the formal aspects of the language, which is likely to enhance critical reflection and thus learner autonomy. Additionally, they can encourage learners to produce the language making use of their both linguistic and metalinguistic knowledge. Regarding that grammatical analysis is necessary for accurate language production (Swain \& Lapkin, 1995, as cited in Roehr, 2000), teachers can carry out brainstorming activities in which they tap learners' opinions of why a certain grammar form is appropriate in one context but not in another (Roehr, 2000). Moreover, grammaticality judgment tasks can be employed in foreign language classes to focus learners' attention on formal aspects of the target language and raise awareness without formal grammar instruction. Furthermore, L2 teachers may provide metalinguistic knowledge and use metalanguage in class for L2 learners' good during self-study, and in order to enable them to gain access to accounts in grammar materials (Berry, 2001),

On the other hand, as Gutierrez (2013) and Elder and Manwaring (2004) note, metalinguistic knowledge may be useful for some structures but not for others. Therefore, teachers should be careful in selecting L2 structures to focus on. Moreover, while focusing on form and attempting to raise awareness of the target language, teachers should try not to trivialise the role of meaning and communicative purposes for learning a foreign language. In addition to this, learners' L1 background and L1 metalinguistic and metalingual awareness should also be taken into consideration because it may be easier for learners to grasp some aspects of the target language once they are familiar with metalinguistic and metalingual aspects of their native language.

\section{Conclusion}

The present study investigated the nature of metalinguistic knowledge among intermediate-level adult Turkish EFL learners and the relationship between this knowledge and L2 production, operationalised in a writing task. Metalinguistic knowledge was assessed both productively and receptively. For the productive metalinguistic knowledge, the participants were asked to read 17 grammatically incorrect $\mathrm{L} 2$ sentences, and underline the incorrect part, correct it, and explain why it was incorrect referring to the rule and using technical words. For the receptive metalinguistic knowledge, the participants were required to read a short text in English and find examples for a list of 25 grammatical features. The findings of the present study revealed that intermediate-level adult Turkish EFL learners participating in the present study appear to have moderate to high metalinguistic knowledge, and their productive metalinguistic knowledge and receptive metalinguistic knowledge did not significantly differ from each other. The findings also revealed that the participants were better at explaining why the sentences in the productive metalinguistic knowledge test were grammatically incorrect than

Investigating the Relationship between Metalinguistic Knowledge and L2 writing among Intermediate-level adult Turkish EFL Learners 
they were at referring to the exact rule and using technical words. Furthermore, a significant moderate correlation was found between the participants' metalinguistic knowledge and their writing accuracy.

The findings of the present study suggest a positive relationship between metalinguistic knowledge and grammatical accuracy in writing among intermediatelevel adult Turkish EFL learners. Therefore, it is recommended that teachers may help learners to connect their metalinguistic knowledge to language production in the forms of production exercises and writing tasks so that they can learn target grammar structures more easily and reinforce what they have already learned. However, the findings of the present study may be considered somehow inconclusive because of the CAF measures and the small sample size. Considering the significance of metalinguistic knowledge for EFL learners and the limitations of the existing studies including the current one, further research is needed.

\section{References}

Alderson, J. C., \& Steel, D. (1994). Metalinguistic knowledge, language aptitude and language proficiency. Retrieved from ERIC database (ED380984).

Alderson, J. C., Clapham, C., \& Steel, D. (1997). Metalinguistic knowledge, language aptitude and language proficiency. Language Teaching Research, 1, 93-121.

Alipour, S. (2014). Metalinguistic and linguistic knowledge in foreign language Learners. Theory and Practice in Language Studies, 4(12), 2640-2645.

Andrews, S. (2006). The evolution of teachers' language awareness. Language Awareness, 15(1), 1-19.

Arthur, B. (1980). Gauging the boundaries of second language competence. A study of learner judgements. Language Learning, 30, 177-194.

Aydın, F. (2018). L2 metalinguistic knowledge and L2 achievement among intermediate-

level adult Turkish EFL learners. Journal of Language and Linguistic Studies, $14(1), 28-49$.

Berko, J. (1958). The child's learning of English morphology. Word, 14, 150-77.

Berry, R. (2005). Making the most of metalanguage. Language Awareness, 14(1), 320.

Bialystok, E. (1990). The competence of processing: Classifying theories of second language acquisition. TESOL Quarterly, 24, 635-48.

Burt, M., \& Kiparsky, C. (1972) The Gooficon: A repair manual for English. Rowley, MA: Newbury House.

Carter, R. (2003). Language awareness. ELT Journal, 57, 64-65.

Dakowska, M. (1993) Language, metalanguage, and language use: A cognitive psycholinguistic view. International Journal of Applied Linguistics, 3, 79-9.

Elder, C., \& Manwaring, D. (2004). The relationship between metalinguistic knowledge and learning outcomes among undergraduate students of Chinese. Language Awareness, 13(3), 145-62.

Elder, C. (2009). Validating a test of metalinguistic knowledge. In R. Ellis, S. Loewen, C. Elder, J. Erlam, J. Philp, \& H. Reinders (Eds.), Implicit and explicit

Investigating the Relationship between Metalinguistic Knowledge and L2 writing among Intermediate-level adult Turkish EFL Learners 
knowledge in second language learning, testing and teaching (pp. 113-138). Bristol, UK: Multilingual Matters.

Ellis, R., \& Barkhuizen, G. (2005). Analyzing learner language. Oxford, UK: Oxford University Press.

Ellis, R. (1994). The study of second language acquisition. Oxford, UK: Oxford University Press.

Ellis, R. (2009). Measuring implicit and explicit knowledge of a second language. In R. Ellis, S. Loewen, C. Elder, J. Erlam, J. Philp, \& H. Reinders (Eds.), Implicit and explicit knowledge in second language learning, testing and teaching (pp. 31-64). Bristol, UK: Multilingual Matters.

Ellis, N. (2011). Implicit and explicit SLA and their interface. In C. Sanz \& R.P. Leow (Eds.), Implicit and explicit language learning. Conditions, processes, and knowledge in SLA and bilingualism (pp. 35-47). Washington, DC: Georgetown University Press.

Gass, S. (1994). The reliability of second-language grammaticality judgments. In E. Tarone, S. Gass, \& A. Cohen (Eds.), Research methodology in secondlanguage acquisition (pp. 303-322). Hillsdale, NJ: Lawrence Erlbaum Associates.

Germain, C., \& Seguin, H. (1995). Le Point sur: La Crammaire. Montreal: Centre Educatif Culturel.

Gutierrez, X. (2012). Implicit knowledge, explicit knowledge, and achievement in second language (L2) Spanish. Canadian Journal of Applied Linguistics, 15, $20-41$.

Gutierrez, X. (2013). Metalinguistic knowledge, metalingual knowledge, and proficiency in L2 Spanish. Language Awareness, 22(2), 176-191.

Gutierrez, X. (2016). Analysed knowledge, metalanguage, and second language proficiency. System, 60, 42-54.

Han, Y., \& Ellis, R. (1998). Implicit knowledge, explicit knowledge and general language proficiency. Language Teaching Research, 2, 1-23.

Housen, A., \& Kuiken, F. (2009). Complexity, accuracy, and fluency in second language acquisition. Applied Linguistics, 30(4), 461-473. doi: 10.1093/applin/amp048.

Hu, G. (2002). Psychological constraints on the utility of metalinguistic knowledge in second language production. Studies in Second Language Acquisition, 24, 347-386.

Kellerman, E. (1986). An eye for an eye: Crosslinguistic constraints on the development of the L2 lexicon. In E. Kellerman \& M. Sharwood Smith (Eds.), Crosslinguistic influence in second language acquisition (pp. 35-48). Oxford: Pergamon.

Kuile, T., H., \& Weldhuis, M. (2010). Bilingual education, metalinguistic awareness, and the understanding of an unknown language. Language and Cognition, 14(2), 233-242.

Larsen-Freeman, D. (2006). The emergence of complexity, fluency, and accuracy in the oral and written production of five Chinese learners of English. Applied Linguistics, 27(4), 590-619. 
Masny, D. (1991) Language learning and linguistic awareness: The relationship between proficiency and acceptability judgments in L2. In C. James \& P. Garret (Eds.), Language awareness in the classroom (pp. 290-304). London: Longman

Mathews, R., Buss, R., Stanley, W., Blanchard-Fields, F., Cho, C., \& Druhan, B. (1989). Role of implicit and explicit processes in learning from examples: a synergistic effect. Journal of Experimental Psychology: Learning, Memory and Cognition, 15, 1083-1100.

Pienemann, M. (1989). Is language teachable? Psycholinguistic experiments and hypotheses. Applied Linguistics, 10, 52-79.

Polio, C. G. (1997). Measures of linguistic accuracy in second language writing research. Language Learning, 47(1), 101-143.

Reber, A. (1989). Implicit learning and tacit knowledge. Journal of Experimental Psychology: General, 118, 219-235.

Renou, J. M. (2000). Learner accuracy and learner performance: The quest for a link. Foreign Language Annals, 33(2), 168-80.

Renou, L. (2001). An examination of the relationship between metalinguistic awareness and second language proficiency of adult learners of French. Language Awareness, 10, 249-67.

Roehr, K. (2007). Metalinguistic knowledge and language ability in university-level L2 learners. Applied Linguistics, 29(2), 173-199.

Roehr, K., \& Ganem-Gutierrez, G. A. (2009). The status of metalinguistic knowledge in instructed adult L2 learning. Language Awareness, 18(2), 165-181.

Sharwood-Smith, M. (1988). Modularity in second language research. Polyglot 9 (Fiche 2, DI).

Steel, D. \& Alderson C. (1994). Metalinguistic knowledge, language aptitude and language proficiency. In D. Graddol \& S. Thomas (Eds.), Language in a Changing Europe (pp. 92-103). Clevedon, England: BAAL and Multilingual Matters.

Swain, M. \& Lapkin, S. (1995). Problems in output and the cognitive processes they generate: A step towards second language learning. Applied Linguistics, 16, 371-391.

Tabachnick, B. G., \& Fidell, L.S. (2012). Using multivariate statistics. London: Pearson.

Tokunaga, M. (2014). Exploring metalinguistic knowledge of low to intermediate proficiency EFL students in Japan. SAGE Open, 1-10. https://journals.sagepub.com/doi/full/10.1177/2158244014553601

VanPatten, B., \& Benati, A. G. (2010). Key terms in second language acquisition. London; New York: Continuum.

Wistner, B. (2014). Effects of metalinguistic knowledge and language aptitude on second language learning. Unpublished Doctoral Thesis. Temple University, Philadelphia.

Wolfe-Quintero, K., Inagaki, S., \& Kim, H. Y. (1998). Second language development in writing: Measures of fluency, accuracy, \& complexity. Honolulu: University of Hawaii Press.

Investigating the Relationship between Metalinguistic Knowledge and L2 writing among Intermediate-level adult Turkish EFL Learners 
Yeşilyurt, S. (2005). The relationship between metalinguistic knowledge and foreign language proficiency. Unpublished Master's Thesis, Atatürk University, Turkey.

Zipke, M. (2007). The role of metalinguistic awareness in the reading comprehension of sixth and seventh graders. Reading Psychology, 28, 375-396. 